\title{
Correction: Correction: Multi-Method Approach for Characterizing the Interaction between Fusarium verticillioides and Bacillus thuringiensis Subsp. Kurstaki
}

Liliana O. Rocha, Sabina Moser Tralamazza, Gabriela M. Reis, Leon Rabinovitch, Cynara B. Barbosa, Benedito Corrêa

Fig 4 is missing portion 4b. Please see the complete, correct Fig 4 here. This correction is in addition to the correction for Fig 2.

\section{f open ACCESS}

Citation: Rocha LO, Tralamazza SM, Reis GM, Rabinovitch L, Barbosa CB, Corrêa B (2015) Correction: Correction: Multi-Method Approach for Characterizing the Interaction between Fusarium verticillioides and Bacillus thuringiensis Subsp. Kurstaki. PLoS ONE 10(10): e0141522. doi:10.1371/ journal.pone.0141522

Published: October 21, 2015

Copyright: ๑ 2015 Rocha et al. This is an open access article distributed under the terms of the Creative Commons Attribution License, which permits unrestricted use, distribution, and reproduction in any medium, provided the original author and source are credited. 
A

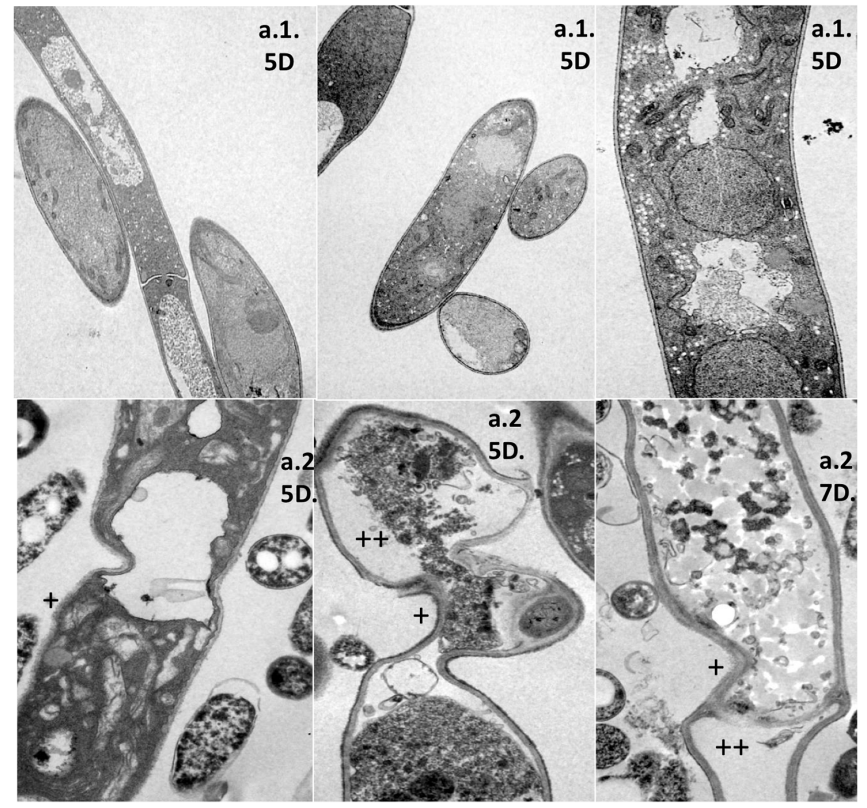

+ Cell wall damage; ++ Citoplasm damage.
B

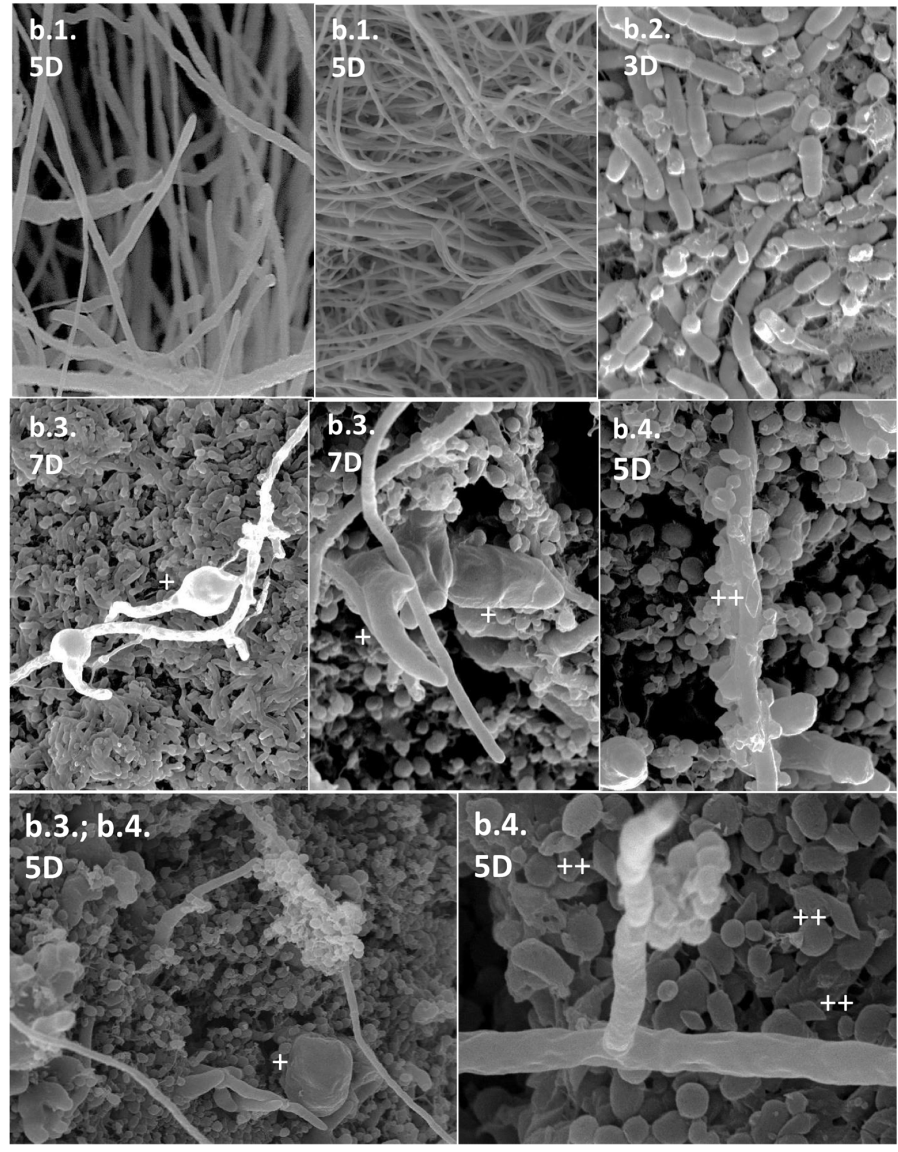

+Intumescent hyphae; ++ Btk crystals.

Fig 4. Microscopic observations of Fusarium verticillioides (Fv) in contact with Bacillus thuringiensis subsp. kurstaki (Btk). Fv and Btk were cocultured on potato dextrose agar and microscopically examined after 5 (5D) and 7 (7D) days of growth. Figure 4(A). Transmission electron microscopy (TEM): $F v$ cells from pure culture (a.1) and with damaged cell walls and disorganization of the cytoplasm-scale bar: $1 \mu \mathrm{m}$ (a.2). Figure 4(B). Scanning electron microscopy (SEM): $F v$ cells from pure culture-scale bars: $10 \mu \mathrm{m}$ and $20 \mu \mathrm{m}$ (b.1); Btk cells from pure culture-scale bar: $10 \mu \mathrm{m}$ (b.2); intumescent hyphae and sparse fungal growth—scale bars: $5 \mu \mathrm{m}, 10 \mu \mathrm{m}$ and $20 \mu \mathrm{m}$ (b.3); and Btk spores and crystals around the hyphae-scale bars: $5 \mu \mathrm{m}$ and $10 \mu \mathrm{m}$ (b.4).

doi:10.1371/journal.pone.0141522.g001

\section{Reference}

1. Rocha LO, Tralamazza SM, Reis GM, Rabinovitch L, Barbosa CB, Corrêa B (2014) Multi-Method Approach for Characterizing the Interaction between Fusarium verticillioides and Bacillus thuringiensis Subsp. Kurstaki. PLoS ONE 9(4): e92189. doi: 10.1371/journal.pone.0092189 PMID: 24739804

2. The PLOS ONE Staff (2014) Correction: Multi-Method Approach for Characterizing the Interaction between Fusarium verticillioides and Bacillus thuringiensis Subsp. Kurstaki. PLoS ONE 9(8): e105840. doi: 10.1371/journal.pone.0105840 